\title{
Human intestinal dendritic cells as controllers of mucosal immunity
}

\author{
David Bernardo
}

Antigen Presentation Research Group. Imperial College London, Northwick Park \& St Mark's Campus. Harrow, United Kingdom

\begin{abstract}
Dendritic cells are the most potent, professional antigen-presenting cells in the body; following antigen presentation they control the type (proinflammatory/regulatory) of immune response that will take place, as well as its location. Given their high plasticity and maturation ability in response to local danger signals derived from innate immunity, dendritic cells are key actors in the connection between innate immunity and adaptive immunity responses. In the gut dendritic cells control immune tolerance mechanisms against food and/or commensal flora antigens, and are also capable of initiating an active immune response in the presence of invading pathogens. Dendritic cells are thus highly efficient in controlling the delicate balance between tolerance and immunity in an environment so rich in antigens as the gut, and any factor involving these cells may impact their function, ultimately leading to the development of bowel conditions such as celiac disease or inflammatory bowel disease. In this review we shall summarize our understanding of human intestinal dendritic cells, their ability to express and induce migration markers, the various environmental factors modulating their properties, their subsets in the gut, and the problems entailed by their study, including identification strategies, differences between humans and murine models, and phenotypical variations along the gastrointestinal tract.
\end{abstract}

Key words: Dendritic cells. Human intestine. Celiac disease. Inflammatory bowel disease. Mucosal immunology. Migration markers.

Received: $26-03-2013$

Accepted: 02-04-2013

Correspondence: David Bernardo. Antigen Presentation Research Group. Imperial College London Northwick Park and St. Mark's Campus, Level 7W St. Mark's Hospital, Watford Road, Harrow, HA1 3UJ, UK

e-mail: d.bernardo-ordiz@imperial.ac.uk

\section{DENDRITIC CELLS}

\section{Dendritic cells as antigen presenters}

Dendritic cells (DCs) are the most potent antigen-presenting cells (APCs) in the body. In contrast to other APCs such as B-lymphocytes or macrophages, DCs are unique in that they can initiate a primary immune response by stimulating naïve T-cells, and control the development of a tolerogenic or proinflammatory immune response (1-6).

DC precursors migrate from the bone marrow to virtually all tissues in the body, including the bowel mucosa. Once in their destination immature, sessile cells are highly efficient in antigen capturing and processing, which allows them to sample their environment $(7,8)$. In addition to their role as sentinels DCs also act as immune system sensors given their high expression of pattern recognition receptors (PRRs), including Toll-like receptors (TLRs) (9-11), as well as their capacity to become activated in the presence of innate immune stress as mediated by cytokines and/or oxygen reactive species $(12,13)$. DCs are therefore the nexus connecting innate (non-antigen specific) immune responses to the highly specialized adaptive immune responses. Once they have captured a "danger antigen" via their PRRs or sensed an immune stress signal DCs lose both sessility and their high antigen-processing capacity, and start migrating to secondary

Bernardo D. Human intestinal dendritic cells as controllers of mucosal immunity. Rev Esp Enferm Dig 2013;105:279-290. 
lymphoid organs in a CCR7-dependent manner $(2,14)$. During migration DCs mature, which manifests as 3 primary changes or signals (15): The first signal is an increased surface expression of processed antigens aided by an increase in HLA molecules. The second signal is an increased expression of co-stimulating molecules such as CD80(B7.1) /CD86(B7.2) (T-cell CD28/CTLA4 ligands) or CD40 (Tcell CD40L ligand). The third signal involves a change in cytokine production that alters the balance between proinflammatory and regulatory cytokines (1-6,15). Once in the secondary lymphoid tissues DCs will have lost their antigen-capturing ability but will be extremely efficient for antigen presentation and in stimulating T-cells, true effectors of immune response. The eventual combination of these 3 antigen presentation signals in terms of intensity and quality will determine the type of immune response (proinflammarory/regulatory) lymphocytes will adopt.

\section{DCs and migration markers}

In addition to controlling the type of immune response (proinflammatory/regulatory) that is established against each specific antigen, DCs also control its location (16). Prior to stimulation näive T-cells express migration markers that lead them to lymphoid tissues (17). Once there, during antigen presentation, DCs deliver a fourth signal and induce the expression of homing markers or migration markers. Specifically, DCs induce in effector lymphocytes homing markers that will lead them to the target tissues where antigens they were trained to recognize are to be found (1821 ), this being the reason why immune responses occur following a tissue-specific rather than a systemic approach.

The mechanisms through which DCs may induce homing markers in effector cells are just beginning to be elucidated, and seem to involve -among other components- fatsoluble vitamins such as vitamin A and vitamin D. The 25-OHD molecule, that may be generated in the skin following the ultraviolet light-dependent activation of vitamin $\mathrm{D}$, induces the expression of skin-homing markers in Tcells (22). In turn, gut DCs possess the enzymatic machinery necessary to synthesize retinoic acid (RA), a metabolite of dietary vitamin A that induces gut-homing marker expression in T-cells (23). However, as we shall discuss below, RA not only controls the intestinal migration capabilities of effector lymphocytes but is also involved in a host of other intestinal immunity mechanisms (24).

\section{TOLEROGENIC DENDRITIC CELLS IN THE GUT}

While the systemic immune system favors the development of an active immune response against foreign antigens, the mucosal immune system operates the other way round; in an environment so rich in antigens like the gut, the intestinal immune system by default gives priority to immune tol- erance mechanisms (25) regarding the commensal flora and food antigens (26). When the immunity-tolerance balance is altered, the immune system may take it wrong and establish an abnormal immune response against the commensal flora and/or dietary antigens, as is the case, respectively, in inflammatory bowel disease (IBD) (27) and celiac disease $(\mathrm{CeD})(28)$.

Intestinal DCs are key cells for the control of immune tolerance mechanisms in an environment so rich in antigens like the gut $(29,30)$. Under normal conditions, in the absence of inflammation, DCs have a regulatory role and prevent the development of immune responses against food antigens and/or the commensal flora $(29,31)$. The lower immunogenic capacity of intestinal DCs results from a number of factors. One of them is that they exhibit a decreased expression of PRRs such as TLRs (30), which grants them a lower capability to identify commensal bacteria in an environment that is loaded with bacterial antigens. In addition, the second signal of antigen presentation is decreased in intestinal DCs because of a reduced expression of co-stimulating molecules in their surface and an increased phagocytic capacity as compared to DCs in other organs $(32,33)$. Finally, the third signal of antigen presentation also tends towards a higher production of regulatory cytokines, including IL-10, rather than proinflammatory cytokines such as IL-6 or IL-12 (30). Under these conditions human intestinal DCs have a reduced stimulating capacity when compared to those in other tissues (21), which is key in maintaining tolerance mechanisms and in preventing inflammatory processes in the absence of invading pathogens $(30,34,35)$. In addition to reduced stimulating capacity intestinal DCs also play an active role in aiding mucosal tolerance by favoring the differentiation of antigenspecific regulatory T-cells and IgA-secreting B-cells (3642). Last, DCs induce the expression of gut-homing markers ( $\alpha 4 \beta 7$ and/or CCR9) both in IgA-secretory B-cells and regulatory T cells (40,44-46), which is key in keeping immune tolerance processes confined in the gut. The relevance of DCs for the control of immune tolerance becomes particularly clear in IBD, where DCs accumulate in the colon (47). Furthermore, these DCs have high levels of co-stimulating molecules and a greater capability to secrete pro-inflammatory cytokines, hence they favor the development of proinflammatory T-cells rather than regulatory lymphocytes (48), thus leading to inflammation and loss of immune tolerance towards the commensal flora.

\section{MIGRATION MARKERS AND INTESTINAL IMMUNITY}

\section{Gut-homing markers}

T-cells migrating to the gut express the $\alpha 4 \beta 7$ heterodimer on their surface (49) since its ligand, the MAdCAM-1 molecule, is expressed by endothelial cells in the lamina propria postcapillary venules of both the small and large bowels (50-52). Another molecule controlling migration to gut tis- 
sues is chemokine receptor CCR9. Its ligand, molecule CCL25/TECK, is expressed by small-bowel epithelial cells (53-55) with a gradient -expression is maximal at the proximal end and gradually decreases in the ileum to become undetectable in the colon (56). However, molecules managing this ìimmunological zip codeî do not seem to only control migration target tissues but also migrating cell types, since monocytes, T-cells and B-cells have been shown to use differential homing markers even when migrating to the same tissue $(57,58)$. These differential mechanisms in the various WBC populations might allow a functional specialization of immune responses in the different segments of the gastrointestinal tract.

\section{Migration markers, inflammatory bowel disease, and extraintestinal manifestations}

The expression of migration markers on T-cells, as well as that of their tissue ligands, keeps immune responses at a local level. In IBD [ulcerative colitis (UC) and Crohn's disease $(\mathrm{CrD})]$ and $\mathrm{CeD}$ MAdCAM-1 expression is increased in the intestinal lamina propria (59-62). This is reflected by a redistribution of circulating $\beta 7^{+} \mathrm{T}$-cells from peripheral blood to intestinal compartments, hence in the lamina propria of these patients a high density of T-cells with increased proinflammatory cytokine secretion may be found. On the other hand, in patients with $\mathrm{CrD}$, DCs located in the mesenteric lymph nodes have the ability to prioritize responding lymphocytes with CCR9 (65). In these same patients an increased expression of the CCL25/TECK ligand in the small bowel (but not in the colon) has been reported, which allows proinflammatory $\mathrm{CCR}^{+} \mathrm{T}$-cell recruitment in thelamina propria (66-67).

Albeit the expression of migration markers and their ligands helps understand the basics of immune responses (tolerogenic/proinflammatory) in the gut, there is evidence to believe these molecules are also responsible for the development of extraintestinal manifestations in IBD. An example may be found in the $\gamma \delta$ T-cell population, particularly important for intestinal immunity mechanisms (68-70). Under normal conditions in the absence of inflammation, circulating $\gamma \delta$ T-cells exhibit a migration pattern that is confined to the gut and characterized by the expression of integrin $\beta 7$ on their surface and absence of CLA, a molecule that controls migration to skin tissues (71). However, in patients with IBD and extraintestinal manifestations such as erythema nodosum there is an aberrant $\gamma \delta$ T-population with a $\beta 7 \mathrm{CLA}^{+}$profile that disappears when patients receive steroids and improve clinically (71). In patients with UC who develop primary sclerosing cholangitis following bile duct inflammation MAdCAM-1 and CCL25 expression has been seen not to be confined to the gut, and these molecules may in contrast be identified in the liver of these patients (72). Finally, some patients with $\mathrm{CrD}$ develop paradoxical extraintestinal inflammation following immunosuppressive therapy with anti-TNF antibodies (73). A recent study has shown that in vitro cultures of peripheral blood mononuclear cells in the presence of infliximab (an anti-TNF $\alpha$ monoclonal antibody) induce changes in the expression of T-cell migration markers (74) that might be involved in the development of the aforementioned paradoxical inflammation.

\section{Migration markers on DCs}

While the study of migration markers has usually been limited to lymphocyte populations, APCs such as DCs also express migration markers that vary according to tissue (21); as with lymphocytes, diseases seem to induce changes in their migration markers.

In patients with active IBD, increased intestinal CCL25/ TECK expression $(66,67)$ seems also involved in an increased recruitment of circulating monocytes, which in turn exhibit an increased expression of CCR9 (75). On the other hand, patients with $\mathrm{CrD}$ restricted to a number of tissues (small-bowel/large-bowel) show an altered expression of migration markers $\beta 7$, CLA and CCR9 on peripheral blood DCs that is correlated with the involved tissue, which again suggests a higher infiltration of DCs in target tissues (76). These changes in migration markers involving circulating populations may therefore be useful as novel diagnostic tools using less invasive approaches or as new therapy targets (16), as will be discussed below.

\section{Migration markers as therapeutic targets}

Given the importance of migration markers, these have revealed themselves as highly interesting therapeutic targets in intestinal diseases $(77,78)$. Natalizumab, a humanized monoclonal antibody against integrin $\alpha 4$, has proven its ability to induce and sustain clinical remission in patients with $\mathrm{CrD}$ by blocking heterodimer $\alpha 4 \beta 7$, the molecule responsible for controlling migration towards the bowel $(79,80)$. However, this therapy might have side effects arising from the fact that migration markers are redundant and different combinations of chemokine receptors and integrins control migration to various tissues in the human body $(16,21)$. Even though its role is poorly understood in noninflammation settings, integrin heterodimer $4 \beta 1$ (VLA-4) regulates lymphocyte passage into the central nervous system (following their interaction with the VCAM adhesion molecule expressed by endothelial cells in inflamed tissues (81). Thus, natalizumab (anti-4) has also proven effective for the treatment of patients with multiple sclerosis (82). Due to code redundance and the fact that different tissues (intestine-brain) partly share their homing markers (integrin $\alpha 4$ ), some patients with $\mathrm{CrD}$ or multiple sclerosis who were treated with natalizumab developed a progressive multifocal leukoencephalopathy because of reactivated latent infection with polyomavirus JC. It may therefore be that inhibiting constitutive lymphocyte traffic to target tissues (presently the brain) may eventually impact systemic immune sur- 
veillance, which in the present case allows the development of latent infection $(83,84)$. In view of the existing code redundance a new generation of monoclonal antibodies against heterodimer 47 has come to light (85), and some have proven efficient for the treatment of patients with IBD, apparently with no systemic immune suppression (86). However, as seen above regarding polyomavirus JC reactivation, these immunosuppressive strategies are not exempt from certain risks that cannot be predicted beforehand.

\section{ENVIRONMENTAL FACTORS AS MODULATORS IN THE GUT}

Intestinal DCs have a number of unique immune particulars allowing them to control immune tolerance processes against food and/or commensal flora antigens (46,87-90). Therefore, one may wonder whether such DCs belong to a separate lineage, one set apart from DCs in other bodily tissues.

\section{DC subpopulations in the gut - CD103/Cx3CR1}

Recent studies have suggested that at least 2 DC subpopulations exist in the intestinal lamina propria, with different characteristics and migration markers. Intestinal DCs may then be classified into tolerogenic DCs (CD103+, CCR7+ and CX3CR1-) and proinflammatory DCs (CD103, CCR7- and CX3CR1+), which control tolerance mechanisms versus food and commensal flora antigens, and trigger immune responses against invading pathogens, respectively (91-93) (Fig. 1). Furthermore, tolerogenic DCs possess the enzymatic machinery (enzyme RALDH2) necessary for vitamin A metabolism and RA generation (Table I). Under basal conditions in the absence of inflammation, DCs newly arrived in the intestine are educated by the tissue microenvironment in order to acquire a regulatory phenotype against non-pathogenic antigens. Conversely, in the presence of a proinflammatory process and/or danger signals these facilitate an ìin situî differentiation of monocytes into proinflammatory DCs (91-94). Such dichotomy should allow to explain the ability of new intestinal DCs to distinguish invading pathogens in a "danger" setting while maintaining commensal flora and nutrient tolerance, which is mediated by DCs extravasated during non-inflammatory processes and having acquired a regulatory phenotype (95).

While this hypothesis is primarily based upon information obtained from murine models, $\mathrm{CD} 103^{+}$cells in human mesenteric lymph nodes share several characteristics with murine DCs, which has been the grounds for the 2 DC populations model $(65,96)$. Indeed, $\mathrm{CD} 103^{+} \mathrm{DCs}$ in the human small bowel are decreased in CeD (97), whereas in patients with diabetes mellitus type 1 they fail to generate regulatory-phenotype T-cells as opposed to healthy controls (98).
However, evidence is larger against this dichotomous model. Although a majority of DCs in the human intestinal lamina propria have a regulatory profile $(21,30,33)$, this is not restricted to the $\mathrm{CD} 103^{+}$population (Table I), which is minoritarian in the human gut (99). Similarly, DCs in the human colonic lamina propria do not express CCR7 (100), which according to this dichotomous model would suggest a proinflammatory role (Table I). However, CX3CR1 (a molecule traditionally associated with proinflammatory DCs in the bowel) is virtually absent in human colonic DCs (99). Therefore, the model including regulatory $\mathrm{CD} 103^{+}$cells and proinflammatory CX3CR $1^{+}$cells is seemingly an oversimplification. New evidence suggests that the CX3CR1 population does not include DCs proper but macrophages (99), which in contrast to traditional considerations would indeed have the ability to migrate to lymph nodes for antigen presentation $(101,102)$. On the other hand, other authors have suggested that the role of the CX3CR1 antigen-presenting cell, whether DCs or macrophages, would be associated with a passive tolerance model regarding invading pathogens. These cells would have the ability to migrate towards the lumen in the presence of infection while becoming loaded with bacterial antigens, thus limiting their potential to access the lamina propria and, therefore, maintaining tolerance $(103,104)$. In summary, it looks like the dichotomous model of DCs in the human bowel is an oversimplification derived from limitations in the study of these cells, as will be discussed below.

\section{Intestinal DC phenotypic plasticity}

New evidence indicates that it is the tissue microenvironment itself that conditions DC phenotype, inducing a regulatory profile on their leaving the blood stream and reaching the gut. DCs in different tissues express different migration markers (21), which are dynamic structures modulated by the microenvironment in which DCs abide $(21,105)$, thus giving proof of DC plasticity. This flexibility on the part of DCs seems to extend to other traits, including their ability to polarize different Th1, Th2 or Treg immune responses depending on their prior exposure to various cytokines and/or microbiota-derived signals (106). In this way, following their conditioning by the local microenvironment, DCs acquire the migration markers corresponding to the tissue they are in, and also the ability to imprint them on responding lymphocytes, thus modulating immune responses by sending effector cells back to the target tissue where the antigen is to be found $(18,21,107)$. In the absence of inflammation, intestinal DCs acquire a regulatory profile following exposure to various ìsedativeî signals secreted by lymphocytes $(93,96,108-110)$ (Fig. 2), including thymic stromal lymphopoietin (TSLP), a number of regulatory cytokines such as TGF- $\beta$ or IL-10 $(40,44,93,96,111,112)$, and most particularly RA.

RA is the active form of vitamin A and is a key factor in the development of immune tolerance. In the presence of 


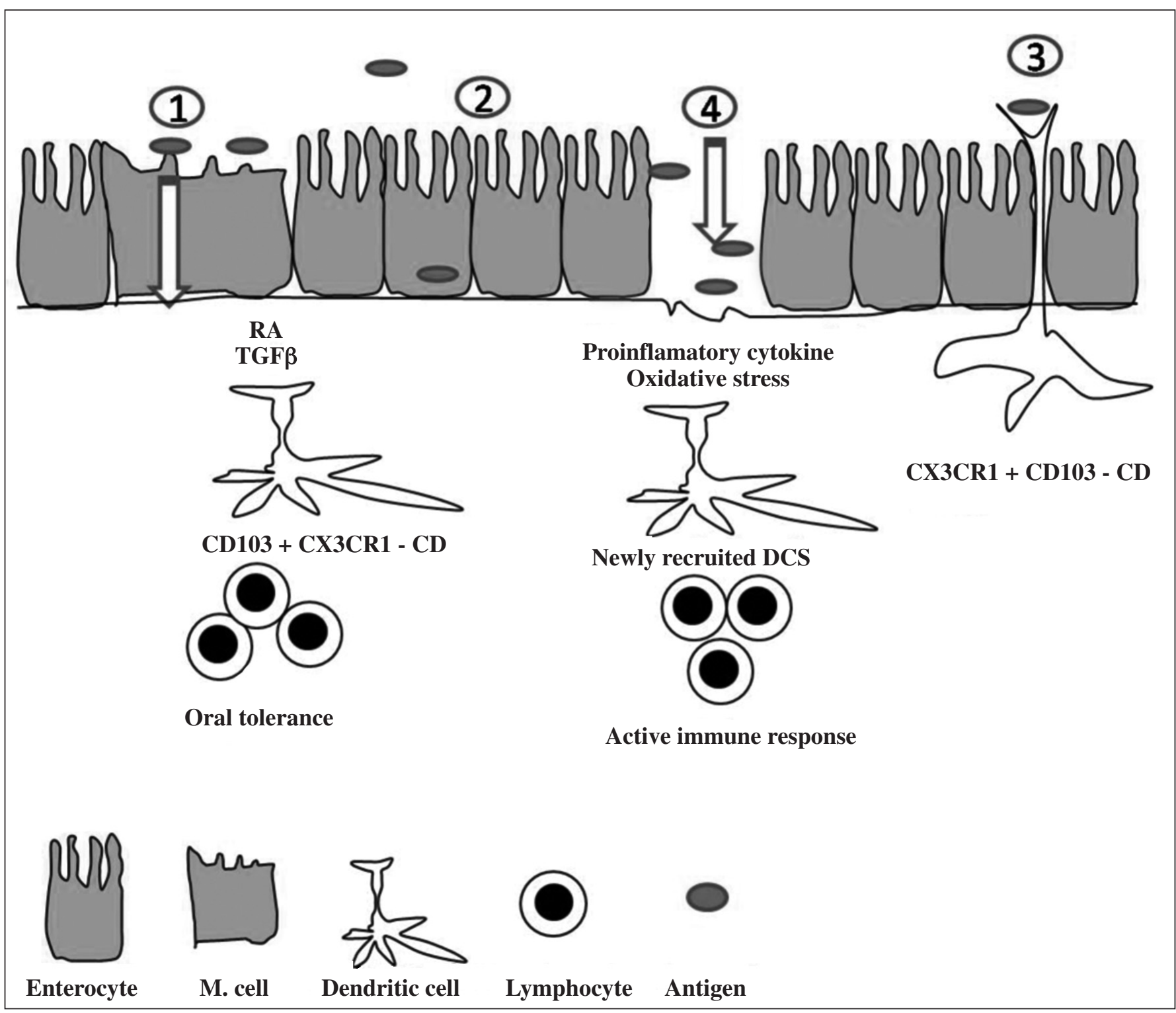

Fig. 1. Dichotomous model of DCs. Antigens may be captured via M-cells at Peyer's patches (1), through enterocyte-derived "tolerosomes" (2), directly by dendritic cells (DCs) emitting dendrites across tight junctions (3), or directly by DCs at the lamina propria when epithelial integrity is compromised (4). In the first two instances the development of oral tolerance is facilitated as mediated by CD103+ DCs trained into a tolerogenic phenotype by enterocytes. Following their interaction with lymphocytes, these DCs favor the development of regulatory T-cells, differentiate B-cells into IgA-secreting cells, and induce in said lymphocytes migration patterns to the gut in order to promote oral tolerance in this organ. In contrast, cells with the ability to emit projections between enterocytes, thus establishing tight junctions through a CX3CR1-dependent mechanism (3), possess an inflammatory phenotype not involved in oral tolerance. Other authors, however, suggest that these CX3CR1 + cells make up the first line of active defense in the gut since they keep on migrating towards the intestinal lumen taking up antigens as they go, which would prevent them from reaching the lamina propria. Finally, in the presence of invading pathogens and/or when epithelial integrity is compromised (4), enterocytes stop emitting tolerogenic signals. Under these conditions, newly recruited DCs at the lamina propria are not differentiated into a homeostatic phenotype given that enterocytes no longer secrete retinoic acid and TGF $\beta$, which together with the presence of innate immune stress favors the differentiation of these DCs into proinflammatory cells. In this setting, the above-mentioned DCs would present antigens to lymphocytes in order to initiate an active immune response.

RA DCs acquire the ability to generate regulatory T-cells and IgA-secreting B-cells, as well as to induce a gut-homing pattern $(40,44-46,88,113)$. RA is therefore essential for intestinal immune tolerance mechanisms, and it is precisely intestinal DCs (but no DCs in other tissues) that possess the enzymatic machinery necessary to convert vitamin A into RA $(65,114,115)$. The intestinal immune system is, however, dynamic -in the presence of a danger signal its regulatory profile disappears as enterocytes stop secreting ìsedativeî signals. This is partly due to the fact that enterocytes themselves have in turn the ability to recognize the presence of invading bacteria. Enterocytes are programmed 


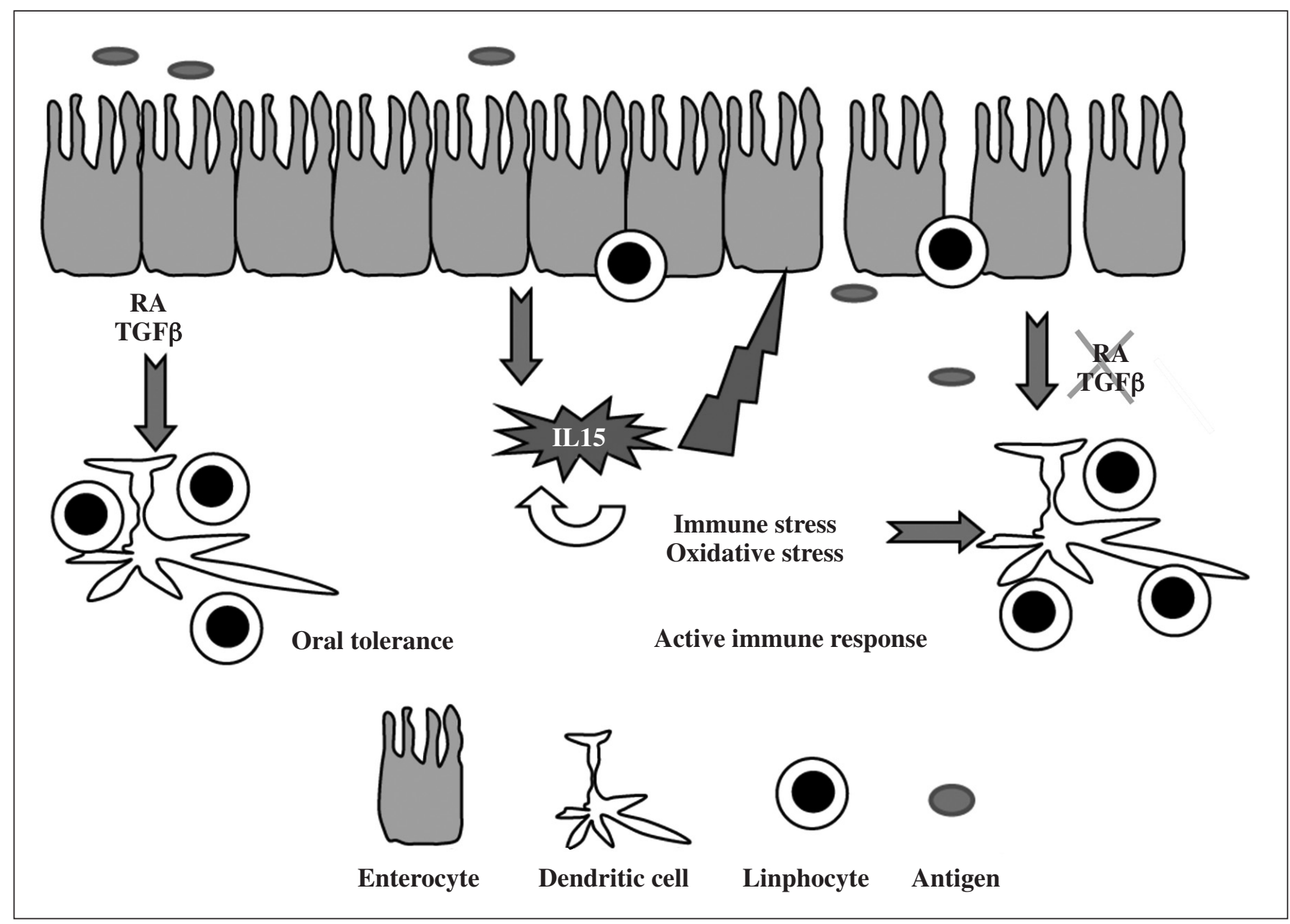

Fig. 2. Functional plasticity model of DCs. Under normal, intestinal homeostasis conditions, enterocytes secrete homeostatic signals such as retinoic acid and TGF $\beta$. In this context dendritic cells (DCs) are trained into a tolerogenic environment that will favor oral tolerance mechanisms. However, in a number of conditions, including inflammatory bowel disease and/or celiac disease, the intestinal homeostasis system is disrupted. While we still do not fully understand the triggering mechanisms involved, in such cases an innate immune response occurs at the enterocyte barrier that is characterized by the presence of proinflammatory cytokines such as IL-15. This innate immune response will favor enterocyte apoptosis mechanisms and tight junction weakening, together with oxidative and immune stress, and will also inhibit the secretion of homeostatic signals by enterocytes. Within this tissue microenvironment newly recruited DCs at the lamina propria are not educated into a homeostatic profile. On the contrary, proinflammatory DCs are generated that capture antigens arriving in the lamina propria for antigen presentation, thus favoring the development of proinflammatory cytokine-secreting lymphocytes that are ultimately involved in tissue injury and the loss of immune tolerance.

Table I. Phenotype and function of the various DC subsets in the gut

\begin{tabular}{lll}
\hline & Proinflammatory & Homeostatic \\
\hline Origin & Monocytes and macrophages & Blood dendritic cells \\
CCR7 & Absent & Present \\
CD103 & Absent & Present \\
RALDH2 & Absent & Present \\
CX3CR1 & Present & Absent \\
\hline
\end{tabular}

to secrete TGF- $\beta$ and RA on recognizing bacteria in their apical membrane by means of their PRRs; however, in the presence of invading bacteria through tight junctions, these germs are recognized by the PRRs located on the basolateral membrane of enterocytes (116-119). In this setting, enterocytes block the secretion of inhibitory signals and consequently DC "sedation". Furthermore, the presence of an innate immune response against invading bacteria involves the secretion of different proinflammatory cytokines and/or oxygen reactive species with the ability to induce DC maturation $(12,13)$. Under such conditions, DCs now recognize and capture antigens as invading pathogens, and block immune tolerance mechanisms to favor those of an active immune response (Fig. 2). This capacity of DCs to rapidly and efficiently respond to their microenvironment grants them the ability to control the immune system and the balance between immunity and tolerance mechanisms. 


\section{PITFALLS IN THE STUDY OF DENDRITIC CELLS}

Despite its huge relevance for the control of immune response type and localization both under normal conditions and during inflammatory processes such as $\mathrm{CeD}$ or IBD $(21,30,33,63,64,120,121)$, the study of DCs is faced with many problems. This is due not only to their low numbers but also to other factors complicating their characterization, including: a) The different species used for their study; b) the identification strategy employed; and c) the studied compartment within the gut.

\section{Differences between mice and humans}

Most of our current understanding of DCs was obtained from murine models. While immunity/tolerance mechanisms may be identical in humans and mice, signaling pathways and involved cell populations may vary considerably (122). An example may be found in the Tgd lymphocyte population in the intraepithelial compartment, which rarely exceeds $20 \%$ in humans but represents up to $50 \%$ in murine models $(122,123)$. Similarly, molecule TLR4 is expressed by murine but not human B-cells (122), whereas FoxP3, seemingly a valid marker for the identification of regulatory T-cells in mice, plays an uncertain role in human beings (124). In addition, the benefits of the microbiota to the intestinal immune system are species-specific (125), and humans also differ from the various murine models in microbiota composition (122).

\section{Identification strategies}

Intestinal DCs and macrophages share a number of both phenotypic and functional characteristics that render their correct classification challenging in the gut (126). Furthermore, multiple cell types have unique markers that facilitate identification $\left(\mathrm{CD}^{+}\right.$for T-cells, CD14 ${ }^{+}$for monocytes, $\mathrm{CD} 19^{+}$for B-cells, etc.), but no marker allowing to characterize DCs has been identified to date.

DC characterization in tissue is usually performed by examining HLA-DR (or other HLA-II molecules) expression and then excluding different cell populations. However, here a new issue emerges since different laboratories use different markers to exclude DCs. In our laboratory we identify DCs as HLA-DR ${ }^{+}$CD3 CD14 CD16 CD19CD34 cells, but other laboratories exclude marker CD14 from their cocktail and/or add marker CD56. However, A DC population that is increased in the lamina propria of patients with UC has been recently characterized (127), which expresses marker CD56 $6^{+}$. This population has not been described (as far as I know) in murine models, but evidence is being increasingly found in the literature focused on their characterization in humans (128-130), even though its role (if any) in the inflammation/tolerance mechanisms found within the gastrointestinal tract remains to be elucidated.

The use of different identification strategies for DCs by the different research teams represents a challenge not only for characterization but also when comparing results. In an attempt to obviate this DC identification issue some authors forget the troublesome differentiation between macrophages and DCs, and alternatively focus on the study of tissuerelated APCs, identified as leukocytes with a high expression of HLA-II molecules $(97,120,131)$. These differences in characterization enable in turn the identification of apparent discrepancies in the literature. Di Sabatino et al. (121) recently identified a plasmacytoid DC subtype in the duodenal lamina propria of celiac subjects that represented a relevant source of IFN and presumably was the origin of most DCs in the celiac lesion. However, other teams have identified no plasmacytoid DCs in the celiac duodenum $(97,120,131)$. Such discrepancies may be accounted for by considering the differing DC identification strategies. Albeit Di Sabatino et al. (121) identified DCs as HLA- $\mathrm{II}^{+}$, lineagenegative cells, other authors insist on APC identification $(97,120,131)$. One of the problems is that plasmacytoid DCs have a decreased expression of HLA-II molecules and so should not be included in the APC compartment because of their reduced HLA-II expression, even if they may be identified using classic DC identification strategies (author's unpublished data). A recent paper seems to point out that this distinct identification strategy is not the origin of the apparent conflict between laboratories (132), which adds a new complicating factor to the study of DCs deriving from sample processing and/or the protocol in use.

Regarding which is the best identification strategy for APCs in the gut, the differences between DCs and macrophages, and the various DC subtypes, this author cannot unfortunately offer a clear answer and recommends an identification strategy according to the question posed, albeit with awareness that every identification approach has limitations, and surely no strategy is better than the next one, all of them being complementary ways to deal with one same problem.

\section{Tissue variations}

Most of our current knowledge on intestinal DCs was obtained from the large bowel. This organ is different from the small bowel, hence it is no wonder that DCs in these two compartments have different immune traits, including a differential expression of CCR7 (100) and different maturation levels (Mann, E.R., personal communication). Variations in DC phenotype may be found even within one single organ. The ascending colon and descending colon exhibit differences in blood supply, enzyme activities $(133,134)$, and enterocyte gene expression (135). In fact, tumors involving both compartments have been traditionally considered differently (136), and new evidence has confirmed these are molecularly differentiated entities 
$(137,138)$. These differences suggest, therefore, the presence of biological differences in the mucosas of both colonic compartments. To confirm this - even though CCR9 is considered a specific small bowel-homing marker, and indeed DCs in the human terminal ileum express said marker- colonic DCs also express the aforementioned marker (99) and there is a differential expression between the ascending and descending colon. In addition, DCs in both sub-compartments differ regarding the expression of molecules involved in bacterial antigen recognition, activation markers, migration markers, cytokine production, and ability to stimulate lymphocytes (manuscript in preparation). Therefore, presuming that DCs represent a single population along the intestinal tract is just another oversimplification, and we should bear in mind the tissue they were obtained from. Similarly, we should also consider the affected tissue when studying intestinal disorders, as DC properties -as well as those of the immune system in general- may vary among tissues. Thus, as is the case with colorectal cancer, which is not a consistent disorder $(137,138)$, IBD may also vary according to involved tissues, and may thus require different treatments depending on its site.

\section{CONCLUSION}

The study of DCs is key in understanding the mechanisms controlling immune responses in the gastrointestinal tract, both under normal conditions in the absence of inflammation and when immune tolerance is compromised. While the study of DCs is no easy task and multiple aspects render characterization difficult, new experimental evidence suggests that we are on the right path to unveiling their complexity and mechanisms of action. When we finally manage to fully decipher the mechanisms by which DCs control oral tolerance, we shall be in a position to understand why in selected conditions such as IBD and CdD the system malfunctions and puts up an immune response against harmless antigens. Above all, notwithstanding, we shall be in a position to develop tailored, tissue- or subtissue-specific therapies, thus obviating the systemic immune modulation problems usually associated with IBD.

\section{ACKNOWLEDGEMENTS}

The author is currently supported by BBSRC funding in the United Kingdom (WMNI P33458).

\section{REFERENCES}

1. Banchereau J, Steinman RM. Dendritic cells and the control of immunity. Nature 1998;392:245-52.

2. Banchereau J, Briere F, Caux C, Davoust J, Lebecque S, Liu YJ, et al. Immunobiology of dendritic cells. Annu Rev Immunol 2000;18:767-811.

3. Shortman K, Liu YJ. Mouse and human dendritic cell subtypes. Nat Rev Immunol 2002;2:151-61.
4. Palucka K, Banchereau J. How dendritic cells and microbes interact to elicit or subvert protective immune responses. Curr Opin Immunol 2002; 14:420-31.

5. Lipscomb MF, Masten BJ. Dendritic cells: Immune regulators in health and disease. Physiol Rev 2002;82:97-130.

6. ONeill HC, Wilson HL. Limitations with in vitro production of dendritic cells using cytokines. Leukoc Biol 2004;75:600-3.

7. Jiang W, Swiggard WJ, Heufler C, Peng M, Mirza A, Steinman RM, et al. The receptor DEC-205 expressed by dendritic cells and thymic epithelial cells is involved in antigen processing. Nature 1995;375:151-5.

8. Sallusto F, Cella M, Danieli C, Lanzavecchia A. Dendritic cells use macropinocytosis and the mannose receptor to concentrate macromolecules in the major histocompatibility complex class II compartment: Downregulation by cytokines and bacterial products. J Exp Med 1995; 182:389-400

9. Benko S, Magyarics Z, Szabó A, Rajnavölgyi E. Dendritic cell subtypes as primary targets of vaccines: the emerging role and cross-talk of pattern recognition receptors. Biol Chem 2008;389:469-85.

10. Granucci F, Zanoni I, Ricciardi-Castagnoli P. Central role of dendritic cells in the regulation and deregulation of immune responses. Mol Life Sci 2008;65:1683-97.

11. Kabelitz D, Wesch D, Oberg HH. Regulation of regulatory T cells: Role of dendritic cells and toll-like receptors. Crit Rev Immunol 2006;26:291-306.

12. Perera PY, Lichy JH, Waldmann TA, Perera LP. The role of interleukin-15 in inflammation and immune responses to infection: implications for its therapeutic use. Microbes Infect 2012;14:247-61.

13. Reis e Sousa. Activation of dendritic cells: Translating innate into adaptive immunity. Curr Opin Immunol 2004;16:21-5.

14. Sallusto F, Schaerli P, Loetscher P, Schaniel C, Lenig D, Mackay CR, et al. Rapid and coordinated switch in chemokine receptor expression during dendritic cell maturation. Eur J Immunol 1998;28:2760-9.

15. Cella M, Sallusto F, Lanzavecchia A. Origin, maturation and antigen presenting function of dendritic cells. Curr Opin Immunol 1997;9:10-6.

16. Hart AL, Ng SC, Mann E, Al-Hassi HO, Bernardo D, Knight SC. Homing of immune cells: role in homeostasis and intestinal inflammation. Inflamm Bowel Dis 2010;16:1969-77.

17. von Andrian UH, Mackay CR. T-cell function and migration. Two sides of the same coin. N Engl J Med 2000;343:1020-34.

18. Stagg AJ, Kamm MA, Knight SC. Intestinal dendritic cells increase T cell expression of alpha4beta7 integrin. Eur J Immunol 2002;32:1445-54.

19. Mora JR, Bono MR, Manjunath N, Weninger W, Cavanagh LL, Rosemblatt M, et al. Selective imprinting of gut-homing T cells by Peyer's patch dendritic cells. Nature 2003;424:88-93.

20. Johansson-Lindbom B, Svensson M, Wurbel MA, Malissen B, Márquez $\mathrm{G}$, Agace W. Selective generation of gut tropic T cells in gut-associated lymphoid tissue (GALT): Requirement for GALT dendritic cells and adjuvant. J Exp Med 2003;198:963-9.

21. Mann ER, Bernardo D, Al-Hassi HO, English NR, Clark SK, et al. Human gut-specific homeostatic dendritic cells are generated from blood precursors by the gut microenvironment. Inflamm Bowel Dis 2012;18:1275-86.

22. Sigmundsdottir H, Pan J, Debes GF, Alt C, Habtezion A, Soler D, et al. DCs metabolize sunlight-induced vitamin D3 to 'program' T cell attraction to the epidermal chemokine CCL27. Nat Immunol 2007; 8:285-93.

23. Iwata M, Hirakiyama A, Eshima Y, Kagechika H, Kato C, Song SY. Retinoic acid imprints gut-homing specificity on $\mathrm{T}$ cells. Immunity 2004;21:527-38.

24. von Boehmer H. Oral tolerance: is it all retinoic acid? J Exp Med 2007;204:1737-9.

25. Macdonald TT, Monteleone G. Immunity, inflammation, and allergy in the gut. Science 2005;307:1920-5.

26. Mowat AM. Anatomical basis of tolerance and immunity to intestinal antigens. Nat Rev Immunol 2003;3:331-41.

27. Strober W, Fuss I, Mannon P. The fundamental basis of inflammatory bowel disease. J Clin Invest 2007;117:514-21.

28. Sollid LM. Coeliac disease: Dissecting a complex inflammatory disorder. Nat Rev Immunol 2002;2:647-55

29. Chirdo FG, Millington OR, Beacock-Sharp H, Mowat AM Immunomodulatory dendritic cells in intestinal lamina propria. Eur J Immunol 2005;35:1831-40. 
30. Hart AL, Al-Hassi HO, Rigby RJ, Bell SJ, Emmanuel AV, Knight SC, et al. Characteristics of intestinal dendritic cells in inflammatory bowel diseases. Gastroenterology 2005;129:50-65.

31. Coombes JL, Maloy KJ. Control of intestinal homeostasis by regulatory T cells and dendritic cells. Semin Immunol 2007;19:116-26.

32. Steinman RM, Hawiger D, Nussenzweig MC. Tolerogenic dendritic cells. Annu Rev Immunol 2003;21:685-711.

33. Bell SJ, Rigby R, English N, Mann SD, Knight SC, Kamm MA, et al. Migration and maturation of human colonic dendritic cells. J Immunol 2001;166:4958-67

34. O'Garra A, Barrat FJ, Castro AG, Vicari A, Hawrylowicz C. Strategies for use of IL-10 or its antagonists in human disease. Immunol Rev 2008;223:114-31.

35. Saraiva M, O'Garra A. The regulation of IL-10 production by immune cells. Nat Rev Immunol 2010;10:170-81.

36. Xiao S, Jin H, Korn T, Liu SM, Oukka M, Lim B, et al. Retinoic acid increases Foxp3+ regulatory T cells and inhibits development of Th17 cells by enhancing TGF-beta-driven Smad3 signaling and inhibiting IL-6 and IL-23 receptor expression. J Immunol 2008;181:2277-84.

37. Benson MJ, Pino-Lagos K, Rosemblatt M, Noelle RJ. All-trans retinoic acid mediates enhanced $\mathrm{T}$ reg cell growth, differentiation, and gut homing in the face of high levels of co-stimulation. J Exp Med 2007; 204:1765-74

38. Sun CM, Hall JA, Blank RB, Bouladoux N, Oukka M, Mora JR, et al. Small intestine lamina propria dendritic cells promote de novo generation of Foxp3 T reg cells via retinoic acid. J Exp Med 2007;204:1775-85.

39. Leithäuser F, Meinhardt-Krajina T, Fink K, Wotschke B, Möller P, Reimann J. Foxp3-expressing CD103+ regulatory T cells accumulate in dendritic cell aggregates of the colonic mucosa in murine transfer colitis. Am J Pathol 2006;168:1898-909.

40. Mora JR, Iwata M, Eksteen B, Song SY, Junt T, Senman B, et al. Generation of gut-homing IgA-secreting B cells by intestinal dendritic cells. Science 2006;314:1157-60.

41. Suzuki K, Maruya M, Kawamoto S, Sitnik K, Kitamura H, Agace WW, et al. The sensing of environmental stimuli by follicular dendritic cells promotes immunoglobulin A generation in the gut. Immunity 2010; 33:71-83.

42. Macpherson AJ, Uhr T. Induction of protective IgA by intestinal dendritic cells carrying commensal bacteria. Science 2004;303:1662-5.

43. Rodrigo Mora J, von Andrian UH. Role of retinoic acid in the imprinting of gut-homing IgA-secreting cells. Semin Immunol 2009;21: 28-35.

44. Strober W. Vitamin A rewrites the ABCs of oral tolerance. Mucosal Immunol 2008;1:92-5.

45. Mora JR, Iwata M, von Andrian UH. Vitamin effects on the immune system: Vitamins A and D take centre stage. Nat Rev Immunol 2008;8:685-98

46. Denning TL, Wang YC, Patel SR, Williams IR, Pulendran B. Lamina propria macrophages and dendritic cells differentially induce regulatory and interleukin 17-producing T cell responses. Nat Immunol 2007; 8:1086-94.

47. Niess JH. Role of mucosal dendritic cells in inflammatory bowel disease. World J Gastroenterol 2008;14:5138-48.

48. te Velde AA, van Kooyk Y, Braat H, Hommes DW, Dellemijn TA, Slors JF, et al. Increased expression of DC-SIGN+IL-12+IL-18+ and CD83+IL-12-IL-18- dendritic cell populations in the colonic mucosa of patients with Crohn's disease. Eur J Immunol 2003;33:143-51.

49. Lefrançois L, Parker CM, Olson S, Muller W, Wagner N, Schön MP, et al. The role of beta7 integrins in CD8 T cell trafficking during an antiviral immune response. J Exp Med 1999;189:1631-8.

50. Berlin C, Berg EL, Briskin MJ, Andrew DP, Kilshaw PJ, Holzmann $\mathrm{B}$, et al. Alpha 4 beta 7 integrin mediates lymphocyte binding to the mucosal vascular addressin MAdCAM-1. Cell 1993;74:185-95.

51. Berg EL, McEvoy LM, Berlin C, Bargatze RF, Butcher EC. L-selectinmediated lymphocyte rolling on MAdCAM-1. Nature 1993;366:695-8.

52. Nakache M, Berg EL, Streeter PR, Butcher EC. The mucosal vascular addressin is a tissue-specific endothelial cell adhesion molecule for circulating lymphocytes. Nature 1989;337:179-81.

53. Zabel BA, Agace WW, Campbell JJ, Heath HM, Parent D, Roberts AI, et al. Human G protein-coupled receptor GPR-9-6/CC chemokine receptor 9 is selectively expressed on intestinal homing $\mathrm{T}$ lymphocytes, mucosal lymphocytes, and thymocytes and is required for thymusexpressed chemokine-mediated chemotaxis. J Exp Med 1999;190:124156.
54. Wurbel MA, Philippe JM, Nguyen C, Victorero G, Freeman T, Wooding $\mathrm{P}$, et al. The chemokine TECK is expressed by thymic and intestinal epithelial cells and attracts double- and single-positive thymocytes expressing the TECK receptor CCR9. Eur J Immunol 2000;30:262-71.

55. Johansson-Lindbom B, Agace WW. Generation of gut-homing T cells and their localization to the small intestinal mucosa. Immunol Rev 2007;215:226-42.

56. Ericsson A, Kotarsky K, Svensson M, Sigvardsson M, Agace W. Functional characterization of the CCL25 promoter in small intestinal epithelial cells suggests a regulatory role for caudal-related homeobox $(\mathrm{Cdx})$ transcription factors. J Immunol 2006;176(6):3642-51.

57. Mora JR. Homing imprinting and immunomodulation in the gut:role of dendritic cells and retinoids. Inflamm Bowel Dis 2008;14:27589.

58. Luster AD, Alon R, von Andrian UH. Immune cell migration in inflammation:present and future therapeutic targets. Nat Immunol 2005 ; 6:1182-90.

59. Souza HS, Elia CC, Spencer J, MacDonald TT. Expression of lymphocyte-endothelial receptor-ligand pairs, alpha4beta7/MAdCAM-1 and OX40/OX40 ligand in the colon and jejunum of patients with inflammatory bowel disease. Gut 1999;45:856-63.

60. Arihiro S, Ohtani H, Suzuki M, Murata M, Ejima C, Oki M, et al. Differential expression of mucosal addressin cell adhesion molecule-1 (MAdCAM-1) in ulcerative colitis and Crohn's disease. Pathol Int 2002;52:367-74.

61. Briskin M, Winsor-Hines D, Shyjan A, Cochran N, Bloom S, Wilson $\mathrm{J}$, et al. Human mucosal addressin cell adhesion molecule-1 is preferentially expressed in intestinal tract and associated lymphoid tissue. Am J Pathol 1997;151:97-110.

62. Di Sabatino A, Rovedatti L, Rosado MM, Carsetti R, Corazza GR, MacDonald TT. Increased expression of mucosal addressin cell adhesion molecule 1 in the duodenum of patients with active celiac disease is associated with depletion of integrin alpha4beta7-positive T cells in blood. Hum Pathol 2009;40:699-704.

63. Hart AL, Kamm MA, Knight SC, Stagg AJ. Quantitative and functional characteristics of intestinal-homing memory T cells: Analysis of Crohn's disease patients and healthy controls. Clin Exp Immunol 2004;135:13745.

64. Hart AL, Kamm MA, Knight SC, Stagg AJ. Prospective evaluation of intestinal homing memory $\mathrm{T}$ cells in ulcerative colitis. Inflamm Bowel Dis 2004;10:496-503.

65. Jaensson E, Uronen-Hansson H, Pabst O, Eksteen B, Tian J, Coombes JL, et al. Small intestinal CD103+ dendritic cells display unique functional properties that are conserved between mice and humans. J Exp Med 2008;205:2139-49.

66. Papadakis KA, Prehn J, Moreno ST, Cheng L, Kouroumalis EA, Deem $\mathrm{R}$, et al. CCR9-positive lymphocytes and thymus-expressed chemokine distinguish small bowel from colonic Crohn's disease. Gastroenterology 2001;121:246-54.

67. Saruta M, Yu QT, Avanesyan A, Fleshner PR, Targan SR, Papadakis KA. Phenotype and effector function of CC chemokine receptor 9expressing lymphocytes in small intestinal Crohn's disease. J Immunol 2007; 178:3293-300.

68. Bhagat G, Naiyer AJ, Shah JG, Harper J, Jabri B, Wang TC, et al. Small intestinal CD8+TCRgammadelta+NKG2A+ intraepithelial lymphocytes have attributes of regulatory cells in patients with celiac disease. J Clin Invest 2008; 118:281-93.

69. Locke NR, Stankovic S, Funda DP, Harrison LC, TCR gamma delta intraepithelial lymphocytes are required for self-tolerance, Immunology 2006;176:6553-9.

70. M. Brandes, K. Willimann, B. Moser, Professional antigen-presentation function by human gammadelta T Cells. Science 2005;309:264-8.

71. Mann ER, McCarthy NE, Peake ST, Milestone AN, Al-Hassi HO, Bernardo D, et al. Skin- and gut-homing molecules on human circulating $\gamma \delta$ T cells and their dysregulation in inflammatory bowel disease. Clin Exp Immunol 2012;170:122-30.

72. Eksteen B, Grant AJ, Miles A, Curbishley SM, Lalor PF, Hübscher $\mathrm{SG}$, et al. Hepatic endothelial CCL25 mediates the recruitment of CCR9+ gut-homing lymphocytes to the liver in primary sclerosing cholangitis. J Exp Med 2004;200:1511-7.

73. Peake STC, Bernardo D, Mann ER, Al-Hassi HO, Knight SC, Hart AL. Mechanisms of action of anti-tumor necrosis factor alpha agents in Crohn's disease. Inflamm Bowel Dis 2013;19:1546-55. 
74. Peake ST, Bernardo D, Mann ER, Al-Hassi HO, Knight SC, Hart AL. Infliximab induces a dysregulated tissue-homing profile on human Tlymphocytes in-vitro: A novel mechanism for paradoxical inflammation? J Crohns Colitis 2013; doi:pii:S1873-9946(13)00019-6. 10.1016/ j.crohns.2013.01.001

75. Linton L, Karlsson M, Grundström J, Hjalmarsson E, Lindberg A, Lindh E, et al. HLA-DR(hi) and CCR9 Define a Pro-Inflammatory Monocyte Subset in IBD. Clin Transl Gastroenterol 2012;doi:10. 1038/ctg.2012.23

76. Peake ST, Bernardo D, Knight SC, Hart AL. Homing marker expression on circulating dendritic cells correlates with different phenotypes of Crohn's disease. J Crohns Colitis 2012 Oct 23. pii:S1873-9946(12) 00424-2. doi:10.1016/j.crohns.2012.10.002.

77. Thomas S, Baumgart DC. Targeting leukocyte migration and adhesion in Crohn's disease and ulcerative colitis. Inflammopharmacology 2012;20:1-18

78. Nishimura M, Kuboi Y, Muramoto K, Kawano T, Imai T. Chemokines as novel therapeutic targets for inflammatory bowel disease. Ann N Y Acad Sci 2009;1173:350-6.

79. Targan SR, Feagan BG, Fedorak RN, Lashner BA, Panaccione R, Present $\mathrm{DH}$, et al. Natalizumab for the treatment of active Crohn's disease:results of the ENCORE Trial. Gastroenterology 2007;132:1672-83.

80. Ghosh S, Goldin E, Gordon FH, Malchow HA, Rask-Madsen J, Rutgeerts $\mathrm{P}$, et al. Natalizumab for active Crohn's disease. N Engl J Med 2003;348:24-32.

81. Irani DN, Griffin DE. Regulation of lymphocyte homing into the brain during viral encephalitis at various stages of infection. J Immunol 1996:156:3850-7.

82. Miller DH, Khan OA, Sheremata WA, Blumhardt LD, Rice GP, Libonati MA, et al. A controlled trial of natalizumab for relapsing multiple sclerosis. N Engl J Med 2003;348:15-23.

83. Langer-Gould A, Atlas SW, Green AJ, Bollen AW, Pelletier D. Progressive multifocal leukoencephalopathy in a patient treated with natalizumab. N Engl J Med 2005;353:375-81.

84. Khalili K, White MK, Lublin F, Ferrante P, Berger JR. Reactivation of JC virus and development of PML in patients with multiple sclerosis. Neurology 2007;68:985-90.

85. Pan WJ, Hsu H, Rees WA, Lear SP, Lee F, Foltz IN, et al. Pharmacology of AMG 181, a human anti- $\alpha$ (4) $\beta(7)$ antibody that specifically alters trafficking of gut-homing T cells. Br J Pharmacol 2013;169:5168.

86. Feagan BG, Greenberg GR, Wild G, Fedorak RN, Paré P, McDonald JW, Treatment of ulcerative colitis with a humanized antibody to the alpha4beta7 integrin. N Engl J Med 2005;352:2499-507.

87. Worbs T, Bode U, Yan S, Hoffmann MW, Hintzen G, Bernhardt G, et al. Oral tolerance originates in the intestinal immune system and relies on antigen carriage by dendritic cells. J Exp Med 2006;203:51927.

88. Kang SG, Lim HW, Andrisani OM, Broxmeyer HE, Kim CH. Vitamin A metabolites induce gut-homing FoxP3+ regulatory T cells. J Immunol 2007:179:3724-33.

89. Sánchez-Sánchez N, Riol-Blanco L, Rodríguez-Fernández JL. The multiple personalities of the chemokine receptor CCR7 in dendritic cells. J Immunol 2006;176:5153-9.

90. Coombes JL, Powrie F. Dendritic cells in intestinal immune regulation. Nat Rev Immunol 2008:8:435-46.

91. Varol C, Vallon-Eberhard A, Elinav E, Aychek T, Shapira Y, Luche $\mathrm{H}$, et al. Intestinal lamina propria dendritic cell subsets have different origin and functions. Immunity 2009;31:502-12.

92. Bogunovic M, Ginhoux F, Helft J, Shang L, Hashimoto D, Greter M, et al. Origin of the lamina propria dendritic cell network. Immunity 2009;31:513-25.

93. Rescigno M. Before they were gut dendritic cells. Immunity 2009;31: 454-6.

94. Ráki M, Tollefsen S, Molberg Ø, Lundin KE, Sollid LM, Jahnsen FL. A unique dendritic cell subset accumulates in the celiac lesion and efficiently activates gluten-reactive T cells. Gastroenterology 2006; 131:428-38

95. Laffont S, Powrie F. Immunology: Dendritic-cell genealogy. Nature 2009;462:732-3.

96. Iliev ID, Spadoni I, Mileti E, Matteoli G, Sonzogni A, Sampietro GM, et al. Human intestinal epithelial cells promote the differentiation of tolerogenic dendritic cells. Gut 2009;58:1481-9.
97. Beitnes AC, Ráki M, Lundin KE, Jahnsen J, Sollid LM, Jahnsen FL Density of CD163+ CD11c+ dendritic cells increases and CD103+ dendritic cells decreases in the coeliac lesion. Scand J Immunol 2011;74:186-94.

98. Badami E, Sorini C, Coccia M, Usuelli V, Molteni L, Bolla AM, et al. Defective differentiation of regulatory FoxP3+ T cells by small-intestinal dendritic cells in patients with type 1 diabetes. Diabetes 2011; 60:2120-4

99. Mann ER, Landy JD, Bernardo D, Peake ST, Hart AL, Al-Hassi HO, et al. Intestinal dendritic cells:Their role in intestinal inflammation, manipulation by the gut microbiota and differences between mice and men. Immunol Lett 2013;150:30-40.

100. Al-Hassi HO, Bernardo D, Murugananthan AU, Mann ER, English NR, Jones A, et al. A mechanistic role for leptin in human dendritic cell migration: Differences between ileum and colon in health and Crohn's disease. Mucosal Immunol 2012. doi:10.1038/mi.2012.113.

101. Cerovic V, Houston SA, Scott CL, Aumeunier A, Yrlid U, Mowat AM, et al. Intestinal CD103(-) dendritic cells migrate in lymph and prime effector T cells. Mucosal Immunol 2013;6:104-13.

102. Diehl GE, Longman RS, Zhang JX, Breart B, Galan C, Cuesta A, et al. Microbiota restricts trafficking of bacteria to mesenteric lymph nodes by CX(3)CR1(hi) cells. Nature 2013;494:116-20.

103. Arques JL, Hautefort I, Ivory K, Bertelli E, Regoli M, Clare S, et al. Salmonella induces flagellin- and MyD88-dependent migration of bacteria-capturing dendritic cells into the gut lumen. Gastroenterology 2009;137:579-87.

104. Nicoletti C, Arques JL, Bertelli E. CX3CR1 is critical for Salmonellainduced migration of dendritic cells into the intestinal lumen. Gut Microbes 2010;1:131-4

105. Dudda JC, Lembo A, Bachtanian E, Huehn J, Siewert C, Hamann A, et al. Dendritic cells govern induction and reprogramming of polarized tissue-selective homing receptor patterns of T cells: Important roles for soluble factors and tissue microenvironments. Eur J Immunol 2005;35:1056-65.

106. Kapsenberg ML. Dendritic-cell control of pathogen-driven T-cell polarization. Nat Rev Immunol 2003;3:984-93.

107. Edele F, Molenaar R, Gütle D, Dudda JC, Jakob T, Homey B, et al. Cutting edge: Instructive role of peripheral tissue cells in the imprinting of T cell homing receptor patterns. J Immunol 2008;181:3745-9.

108. Rimoldi M, Chieppa M, Salucci V, Avogadri F, Sonzogni A, Sampietro $\mathrm{GM}$, et al. Intestinal immune homeostasis is regulated by the crosstalk between epithelial cells and dendritic cells. Nat Immunol 2005;6:507-14.

109. Butler M, Ng CY, van Heel DA, Lombardi G, Lechler R, Playford RJ, et al. Modulation of dendritic cell phenotype and function in an in vitro model of the intestinal epithelium. Eur J Immunol 2006;36:864-74.

110. Iliev ID, Mileti E, Matteoli G, Chieppa M, Rescigno M. Intestinal epithelial cells promote colitis-protective regulatory T-cell differentiation through dendritic cell conditioning. Mucosal Immunol 2009:2:340-50.

111. Belardelli F, Ferrantini M. Cytokines as a link between innate and adaptive antitumor immunity. Trends Immunol 2002;23:201-8.

112. Ueno H, Klechevsky E, Morita R, Aspord C, Cao T, Matsui T, et al. Dendritic cell subsets in health and disease. Immunol Rev 2007;219: $118-42$.

113. Sigmundsdottir H, Butcher EC. Environmental cues, dendritic cells and the programming of tissue-selective lymphocyte trafficking. Nat Immunol 2008;9:981-7.

114. Coombes JL, Siddiqui KR, Arancibia-Cárcamo CV, Hall J, Sun CM, Belkaid Y, et al. A functionally specialized population of mucosal CD103+ DCs induces Foxp3+ regulatory T cells via a TGF-beta and retinoic acid-dependent mechanism. J Exp Med 2007;204:1757-64.

115. Johansson-Lindbom B, Svensson M, Pabst O, Palmqvist C, Marquez G, Förster R, et al. Functional specialization of gut CD103+ dendritic cells in the regulation of tissue-selective T cell homing. J Exp Med 2005;202:1063-73.

116. Lee J, Mo JH, Katakura K, Alkalay I, Rucker AN, Liu YT, et al. Maintenance of colonic homeostasis by distinctive apical TLR9 signalling in intestinal epithelial cells. Nat Cell Biol 2006;8:1327-36.

117. Lee J, Mo JH, Shen C, Rucker AN, Raz E. Toll-like receptor signaling in intestinal epithelial cells contributes to colonic homoeostasis. Curr Opin Gastroenterol 2007;23:27-31.

118. Pott J, Hornef M. Innate immune signalling at the intestinal epithelium in homeostasis and disease. EMBO Rep 2012;13:684-98. 
119. Wells JM, Rossi O, Meijerink M, van Baarlen P. Epithelial crosstalk at the microbiota-mucosal interface. Proc Natl Acad Sci U S A 2011;108(Supl. 1):4607-14

120. Ráki M, Tollefsen S, Molberg $\varnothing$, Lundin KE, Sollid LM, Jahnsen FL. A unique dendritic cell subset accumulates in the celiac lesion and efficiently activates gluten-reactive T cells. Gastroenterology 2006; 131:428-38

121. Di Sabatino A, Pickard KM, Gordon JN, Salvati V, Mazzarella G, Beattie RM, et al. Evidence for the role of interferon-alfa production by dendritic cells in the Th1 response in celiac disease. Gastroenterology 2007; $133: 1175-87$.

122. Gibbons DL, Spencer J. Mouse and human intestinal immunity: Same ballpark, different players; different rules, same score. Mucosal Immunol 2011;4:148-57.

123. Leon F, Camarero C, Eiras P, Roy G. Specificity of IEL profiling in the diagnosis of celiac disease. Am J Gastroenterol 2004;99:958.

124. Bernardo D, Al-Hassi HO, Mann ER, Tee CT, Murugananthan AU, Peake ST, et al. T-cell proliferation and forkhead box P3 expression in human T cells are dependent on T-cell density: Physics of a confined space? Hum Immunol 2012;73:223-31.

125. Chung H, Pamp SJ, Hill JA, Surana NK, Edelman SM, Troy EB, et al. Gut immune maturation depends on colonization with a host-specific microbiota. Cell 2012;149:1578-93.

126. Pabst $\mathrm{O}$, Bernhardt $\mathrm{G}$. The puzzle of intestinal lamina propria dendritic cells and macrophages. Eur J Immunol 2010;40:2107-11.

127. Ng SC, Plamondon S, Al-Hassi HO, English N, Gellatly N, Kamm MA et al. A novel population of human CD56+ human leucocyte antigen Drelated (HLA-DR+) colonic lamina propria cells is associated with inflammation in ulcerative colitis. Clin Exp Immunol 2009; 158:205-18.

128. Anguille S, Lion E, Tel J, de Vries IJ, Couderé K, Fromm PD, et al. Interleukin-15-induced CD56(+) myeloid dendritic cells combine potent tumor antigen presentation with direct tumoricidal potential. PLoS One 2012;7(12):e51851.
129. Tel J, Smits EL, Anguille S, Joshi RN, Figdor CG, de Vries IJ. Human plasmacytoid dendritic cells are equipped with antigen-presenting and tumoricidal capacities. Blood 2012;120:3936-44.

130. Roothans D, Smits E, Lion E, Tel J, Anguille S. CD56 marks human dendritic cell subsets with cytotoxi potential. OncoImmunology 2013;2:1-3.

131. Beitnes AC, Ráki M, Brottveit M, Lundin KE, Jahnsen FL, Sollid LM Rapid accumulation of CD14+CD11c+ dendritic cells in gut mucosa of celiac disease after in vivo gluten challenge. PLoS One 2012;7 (3):e33556.

132. Ráki M, Beitnes AC, Lundin KE, Jahnsen J, Jahnsen FL, Sollid LM. Plasmacytoid dendritic cells are scarcely represented in the human gut mucosa and are not recruited to the celiac lesion. Mucosal Immunol 2013; doi:10.1038/mi.2012.136.

133. Seitz HK, Egerer G, Oneta C, Krämer S, Sieg A, Klee F, et al. Alcohol dehydrogenase in the human colon and rectum. Digestion 1996;57:1058.

134. Simrén M, Stotzer PO, Sjövall H, Abrahamsson H, Björnsson ES Abnormal levels of neuropeptide $\mathrm{Y}$ and peptide $\mathrm{YY}$ in the colon in irritable bowel syndrome. Eur J Gastroenterol Hepatol 2003;15:55-62.

135. Glebov OK, Rodriguez LM, Nakahara K, Jenkins J, Cliatt J, Humbyrd $\mathrm{CJ}$, et al. Distinguishing right from left colon by the pattern of gene expression. Cancer Epidemiol Biomarkers Prev 2003;12:755-62.

136. Benedix F, Schmidt U, Mroczkowski P, Gastinger I, Lippert H, Kube $\mathrm{R}$ et al. Colon carcinoma -classification into right and left sided cancer or according to colonic subsite? Analysis of 29,568 patients. Eur J Surg Oncol 2011;37:134-9.

137. Komuro K, Tada M, Tamoto E, Kawakami A, Matsunaga A, Teramoto $\mathrm{K}$, et al. Right- and left-sided colorectal cancers display distinct expression profiles and the anatomical stratification allows a high accuracy prediction of lymph node metastasis. J Surg Res 2005;124:216-24.

138. Bauer KM, Hummon AB, Buechler S. Right-side and left-side colon cancer follow different pathways to relapse. Mol Carcinog 2012;51:411-21. 